\title{
Current Processing Current Tunable Universal Biquad Filter Employing Two CCTAs and Two Grounded Capacitors
}

\author{
Ravindra Singh Tomar ${ }^{1}$, Sajai Vir Singh ${ }^{2}$, Durg Singh Chauhan ${ }^{3}$ \\ ${ }^{1}$ Department of Electronics Engineering, Anand Engineering College, Agra, India \\ ${ }^{2}$ Department of Electronics and Communications, Jaypee Institute of Information Technology, Noida, India \\ ${ }^{3}$ Department of Electrical Engineering, Indian Institute of Technology, Banaras Hindu University, Varanasi, India \\ Email: r_tomar15@rediffmail.com, sajaivir@rediffmail.com,pdschauhan@gmail.com
}

Received July 10, 2013; revised August 10, 2013; accepted August 17, 2013

Copyright (C) 2013 Ravindra Singh Tomar et al. This is an open access article distributed under the Creative Commons Attribution License, which permits unrestricted use, distribution, and reproduction in any medium, provided the original work is properly cited.

\begin{abstract}
This paper presents a current processing current-tunable universal biquad filter employing two current conveyor transconductance amplifiers (CCTAs) as active element and two grounded capacitors as passive element. It realizes all the five standard filtering responses such as low pass (LP), band pass (BP), high pass (HP), band reject (BR) and all pass (AP) through appropriate selection of applied current inputs. Proposed circuit does not require minus input current signal and double input current signal to realize different filtering responses. It also does not require component matching condition to realize any filtering responses. Moreover, the circuit offers the advantage of orthogonal electronic tunability of pole-frequency and quality factor. The circuit exhibits low active and passive sensitivities. The circuit performance is verified through P-SPICE simulation software.
\end{abstract}

Keywords: Biquad; Current-Mode; Universal Filter; CCTA

\section{Introduction}

The applications, advantages and realizations of high performance continuous-time (CT) current-mode (also called current processing) active filters have been receiving considerable attention, since the last few decades $[1,2]$. Thus, a number of papers deal with the design of biquad current-mode (CM) filter in the literature [3-27] using different current-mode active elements. However, all of them are realized either in the form of the singleinput multiple-output (SIMO) or multiple-input single output (MISO) category. SIMO filters [3-13] simultaneously realize different filtering functions (in general three or more) at different outputs, without changing the connection of the input signal. On the other hand MISO filters [15-27] can realize multifunction filtering responses at single output terminal by altering the way in which multi-input signals are connected. Moreover, the MISO configuration in comparison with SIMO configuration may lead to a reduction in number of active elements for circuit realization and hence, seems to be more suitable than that of SIMO configuration to realize all the standard biquad filter functions. However, one critical issue with CT filters is the $\mathrm{RC}$ time constant variation problem due to process tolerance, the environmental effects of temperature drift, humidity and aging of the components [14]. As a consequence, the performance of the filter circuit differs from the nominal design. The continuoustime filter approach typically compensates for this problem with the tunable filter, by electronically varying the time constant. So there is a growing interest towards designing of electronically tunable filters to compensate for deviation in the circuit due to process tolerance, parasitic, temperature drift and component aging. During the last one decade and recent past, several electronically tunable MISO type current-mode active filters have been proposed in the literature [15-27], using different currentmode active elements such as second generation current controlled current conveyor (CCCII) [15-21], current differencing transconductance amplifier (CDTA) [22], current follower transconductance amplifier (CFTA) [23], voltage differencing transconductance amplifier (VDTA) [24], current controlled transconductance amplifier (CCTA) [25] and current controlled current conveyor transconductance amplifier (CCCCTA) [26,27] etc.

Each MISO current-mode filter based on CCCII re- 
ported in [15-21] uses two [15-17] or more [18-20] CCCIIs and two grounded capacitors but all of them [15-20] require minus input current signal(s) [15-20] and/or component matching conditions $[18,20]$ to realize at least one filter function. Thus, they need one or more active component to obtain minus input current signal/matching condition. The single CCCII-based current-mode filter [21] with three input single output uses two grounded capacitors and one resistor. However, it still needs minus input current signal(s) to realize BP, BR and AP filter functions. Few more three input single output currentmode filters based on two active elements in the form of CDTA [22], CFTA [23], VDTA [24] and CCTA [25] are also proposed in the literature. Each circuit [22-25] consists of two grounded capacitors and realizes all the standard filtering functions but they also require minus input current signal(s) [22-24] or/and double input current signal(s) [22-25] to realize at least one filter function. Other novel circuits based on two CCCCTAs [26,27] each having two grounded capacitors can also be used as three input single output tunable current-mode filter but they still require minus input current signal [26] or matching conditions [27] to realize AP response.

In this paper, a current processing current-tunable universal biquad filter is proposed which consists of two current conveyor trans-conductance amplifiers (CCTAs) and two grounded capacitors. It can realize LP, BP, HP, $\mathrm{BR}$ and $\mathrm{AP}$ in the current form at high impedance output through appropriate selection of the input signals, without any matching conditions. Moreover, the proposed circuit realizes all the filtering responses without requiring any minus input current signal and double input current signal. Also, the circuit offers the advantage of electronic tunability of pole-frequency independent of quality factor. The circuit exhibits low active and passive sensitivities. The circuit is simulated through P-SPICE simulation.

\section{CCTA and Proposed Biquad Filter}

The CCTA $[13,25]$ is a combination of second generation current conveyor (CCII) and operation transconductance amplifier (OTA). The block diagram of the CCTA is shown in Figure 1. It consists of two input terminals $(X$, $Y$ ). Port $X$ is low input impedance terminal while port $Y$ is the high input impedance terminal. Port $\pm Z$ and port \pm $O$ are the high output impedance terminals. The inputoutput current-voltage relationship between different terminals of the CCTA can be described by the following equations.

$$
I_{Y}=0, V_{X}=V_{Y}, I_{ \pm Z}= \pm I_{X}, I_{ \pm O}= \pm g_{m} V_{Z}
$$

where $g_{m}$ is the trans-conductance of CCTA and depends upon the biasing current $I_{s}$ of the CCTA. The MOS implementation of CCTA is proposed in Figure 2. For a

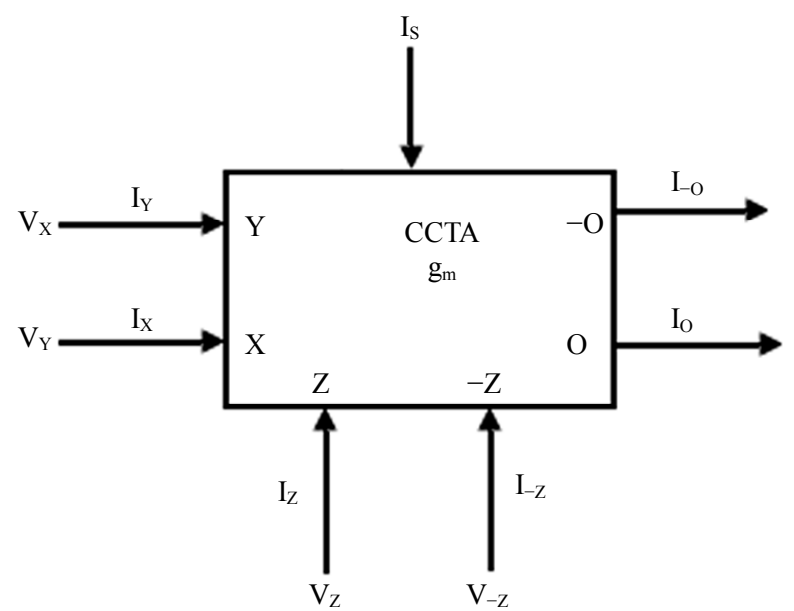

Figure 1. CCTA symbol.

MOS CCTA, the $g_{m}$ can be expressed as

$$
g_{m}=\sqrt{\beta_{n} I_{s}}
$$

Where $\beta_{n}$ is given by

$$
\beta_{n}=\mu_{n} C_{O X} \frac{W}{L}
$$

where $\mu_{n}, C_{O X}$ and $W / L$ are the electron mobility, gate oxide capacitance per unit area and transistor aspect ratio of M13 and M14 NMOS, respectively.

The proposed current-processing universal filter with three inputs $\left(I_{1}, I_{2}\right.$ and $\left.I_{3}\right)$ and single output $\left(I_{\text {out }}\right)$ is shown in Figure 3. The circuit employs only two CCTAs and two grounded capacitors. A routine analysis of the circuit in Figure 3 yields the following current output expression.

$$
I_{\text {out }}=\frac{-\left(s^{2} C_{1} C_{2} I_{1}-s C_{2} g_{m 2} I_{2}+g_{m 1} g_{m 2} I_{3}\right)}{D(s)}
$$

Where

$$
D(s)=s^{2} C_{1} C_{2}+s C_{2} g_{m 2}+g_{m 1} g_{m 2}
$$

It is evident from (4) that various biquad filtering responses in current form can be obtained at current output $\left(I_{\text {out }}\right)$ through appropriate selection of input currents.

1) Inverted HP response at $I_{o u t}$, with $I_{1}=I_{i n}$, and $I_{2}=I_{3}$ $=0$.

2) Inverted LP response at $I_{\text {out }}$, with $I_{3}=I_{\text {in }}, I_{1}=I_{2}=0$.

3) Non-inverted BP response at $I_{\text {out }}$, with $I_{2}=I_{\text {in }}$, and $I_{1}=I_{3}=0$.

4) Inverted BR response at $I_{\text {out }}$, with $I_{1}=I_{3}=I_{\text {in }}$, and $I_{2}$ $=0$.

5) Inverted AP response at $I_{\text {out }}$, with $I_{1}=I_{2}=I_{3}=I_{\text {in }}$, thus, the circuit is capable of realizing all the standard filtering responses in current form from the same configuration. Moreover, there is no requirement of minus- 


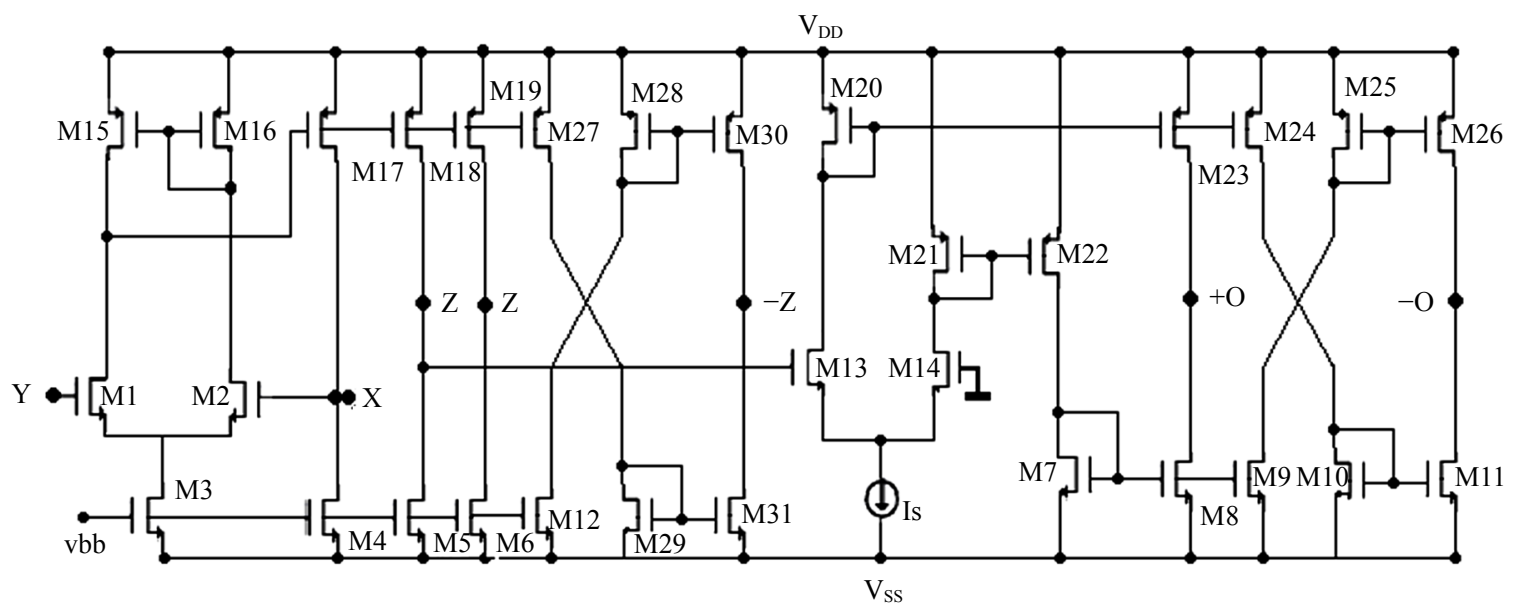

Figure 2. CMOS implementation of CCTA.

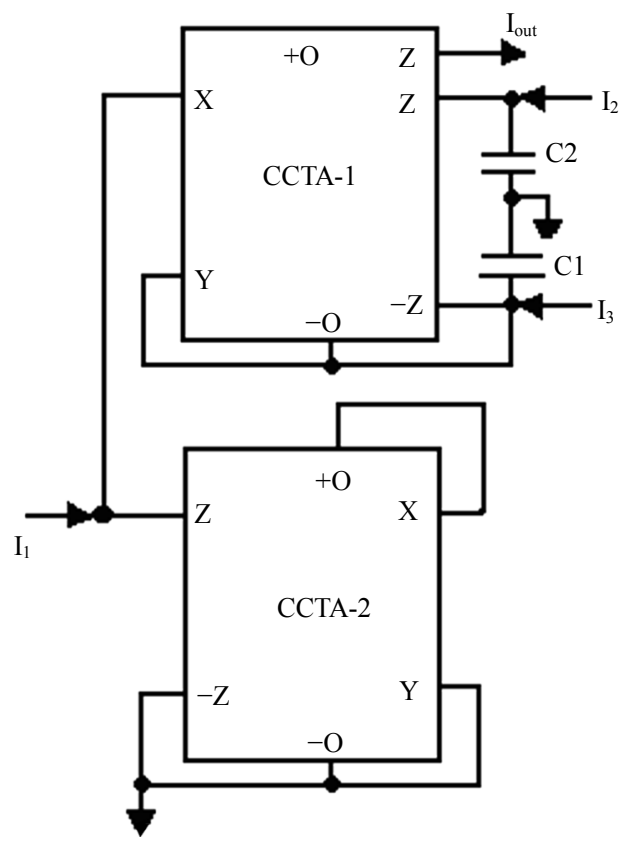

Figure 3. Proposed universal current-processing biquad filter.

type input current signal(s) and double input current signal(s) to realize all the responses in the design. Moreover, the proposed circuit also realizes all filtering responses without any component matching condition. The filter parameters such as pole frequency $\left(\omega_{0}\right)$ and quality factor $\left(Q_{0}\right)$ can be formulated as

$$
\begin{aligned}
& \omega_{0}=\sqrt{\frac{g_{m 1} g_{m 2}}{C_{1} C_{2}}}=\sqrt{\frac{\beta_{n} \sqrt{I_{S 1} I_{S 2}}}{C_{1} C_{2}}} \\
& Q_{0}=\sqrt{\frac{g_{m 1} C_{1}}{g_{m 2} C_{2}}}=\sqrt{\frac{C_{1}}{C_{2}} \sqrt{\frac{I_{S 1}}{I_{S 2}}}}
\end{aligned}
$$

From (6) and (7), it can be noted that the pole frequency can be adjusted by $I_{S 1}$ and $I_{S 2}$ without affecting the quality factor by keeping the ratio of $I_{S 1}$ and $I_{S 2}$ as constant. Similarly, $Q_{0}$ can also be adjusted by $I_{S 1}$ and $I_{S 2}$ without affecting the pole frequency by keeping the product of $I_{S 1}$ and $I_{S 2}$ as constant. In addition, bandwidth $(B W)$ of the system can be expressed by

$$
B W=\frac{\omega_{0}}{Q_{0}}=\frac{g_{m 2}}{C_{1}}=\frac{\sqrt{\beta_{n} I_{S 2}}}{C_{1}}
$$

It can also be noted that $\omega_{0}$ and $Q_{0}$ of the filter can be simultaneously controlled independent of the $B W$ through $I_{S 1}$.

\section{Non-Ideal Aspects}

A non-ideal CCTA, implemented with the transistors is characterized by finite voltage, current and trans-conductance tracking errors occurred due to the mismatching in the transistors. Therefore, taking the non-idealities of the CCTA into account, the relationship of the terminals voltage and current of the $i^{\text {th }}$ CCTA described by (1) can be modified by (9) which is as follows

$$
\begin{aligned}
& I_{Y i}=0, V_{X i}=\beta_{i} V_{Y i}, I_{Z i}=\alpha_{p i} I_{X i}, \\
& I_{-Z i}=-\alpha_{n i} I_{X i}, I_{ \pm O i}= \pm \gamma_{i} g_{m i} V_{Z i}
\end{aligned}
$$

Where $\alpha_{p i}, \alpha_{n i}, \beta_{i}$ and $\gamma_{i}$ are the tracking errors of $i^{\text {th }}$ CCTA $\left(i^{\text {th }}=1,2\right)$ and practically deviated from unity. Taking the non-idealities of CCTA given in (9) into consideration and re-analyzing the circuit of Figure 3, the current response of the proposed circuit of Figure 3 are changed to

$$
I_{\text {out }}=\frac{-\left(s^{2} C_{1} C_{2} I_{1}-\beta_{1} s C_{2} g_{m 2} I_{2}+\gamma_{1} \beta_{1} g_{m 1} g_{m 2} I_{3}\right)}{D(s)}
$$

Where

$$
D(s)=s^{2} C_{1} C_{2}+\beta_{1} \alpha_{n 1} s C_{2} g_{m 2}+\beta_{1} \alpha_{p 1} \gamma_{1} g_{m 1} g_{m 2}
$$

With involved non-idealities, $\omega_{0}, Q_{0}$ and $B W$ are modified to 


$$
\begin{gathered}
\omega_{0}=\sqrt{\frac{\beta_{1} \alpha_{p 1} \gamma_{1} g_{m 1} g_{m 2}}{C_{1} C_{2}}} \\
B W=\frac{\beta_{1} \alpha_{n 1} g_{m 2}}{C_{1}} \\
Q_{0}=\frac{1}{\alpha_{n 1}} \sqrt{\frac{\alpha_{p 1} \gamma_{1} g_{m 1} C_{1}}{\beta_{1} g_{m 2} C_{2}}}
\end{gathered}
$$

This shows that $\omega_{0}$ and $Q$ for the ideal current-mode filter are slightly affected by non-ideal tracking errors. Sensitivity analysis of the proposed filter with respect to active and passive elements yields

$$
\begin{gathered}
S_{C_{1}, C_{2}}^{\omega_{0}}=-\frac{1}{2}, S_{\beta_{1}, \alpha_{p 1}, \gamma_{1}, g_{m 1}, g_{m 2}}^{\omega_{0}}=\frac{1}{2} \\
S_{\alpha_{n 1}, \alpha_{p 2}, \alpha_{n 2}, \gamma_{2}, \beta_{2}}^{\omega_{0}}=0 \\
S_{C_{2}, g_{m 2}, \beta_{1}}^{Q_{0}}=-\frac{1}{2}, S_{\gamma_{1}, \alpha_{p 1}, C_{1}, g_{m 1}}^{Q_{0}}=\frac{1}{2} \\
S_{\alpha_{n 1}}^{Q_{0}}=-1, S_{\alpha_{p 2}, \alpha_{n 2}, \gamma_{2}, \beta_{2}}^{Q_{0}}=0
\end{gathered}
$$

From above results, it can be found that all the active and passive sensitivity are within "unity" in magnitude and hence, proposed circuit ensures a good sensitivity performance.

\section{Simulation Results}

To verify the theoretical analysis of the proposed currentprocessing filter circuit of Figure 3, PSPICE simulation has been used. In simulation, the CCTA was realized using CMOS implementation as shown in Figure 2. The MOS transistors were simulated using 0.35 um MOS process parameters from TSMC (the model parameters are given in Table 1). The supply voltages were $\mathrm{V}_{\mathrm{DD}}=$ $-\mathrm{V}_{\mathrm{SS}}=1.75 \mathrm{~V}$ and $\mathrm{V}_{\mathrm{bb}}=-0.55 \mathrm{~V}$. The dimensions of M13 and M14 NMOS were determined as $\mathrm{W}=14 \mu \mathrm{m}$ and $\mathrm{L}=2 \mu \mathrm{m}$ while the dimensions of all remaining NMOS were determined as $\mathrm{W}=10 \mu \mathrm{m}$ and $\mathrm{L}=2 \mu \mathrm{m}$. In PMOS transistors, the dimensions were $\mathrm{W}=10 \mu \mathrm{m}$ and $\mathrm{L}=1 \mu \mathrm{m}$. The circuit was designed with $I_{S 1}=I_{S 2}=100$ $\mu \mathrm{A}$, and $C_{1}=C_{2}=26 \mathrm{pF}$. Figure 4 shows the simulated current gain and phase responses of BP, LP, HP, BR and AP for the proposed current-mode filter. The simulation results show the simulated pole frequency as $2.04 \mathrm{MHz}$ that agree quite well with the theoretical analysis. Figures 5 and 6 shows the responses of BP and BR functions, respectively, where $\mathrm{I}_{\mathrm{S} 1}$ and $\mathrm{I}_{\mathrm{S} 2}$ were equally set and changed for several values, by keeping its ratio to be constant for constant $Q_{0}(=1)$. From Figures 5 and 6, it can be seen that pole frequency can be electronically tuned by the bias currents $\left(I_{S 1}\right.$ and $\left.I_{S 2}\right)$ without affecting quality factor. Similarly, $Q_{0}$ tunability independent of pole frequency is shown in Figures $\mathbf{7}$ and 8 which display the BP and BR responses, respectively, for different sets of value of $I_{S 1}$ and $I_{S 2}$ with their product to be maintained as constant. The time domain response of currentmode HP output is shown in Figure 9. It was observed that $120 \mu \mathrm{A}$ peak to peak input current sinusoidal signal levels having frequency $40 \mathrm{MHz}$ are possible without significant distortions.

\section{Conclusion}

In this paper, a new current processing current tunable universal biquad filter employing two CCTAs and two grounded capacitors is proposed. The proposed filter offers the following advantages: 1) employment of only two active elements; 2) ability of realizing all current-mode standard filtering functions; 3 ) employment of minimum number of grounded capacitors (only two) to realize any biquad filtering function; 4) low sensitivity figures; 5) electronically orthogonal tunability of $\omega_{0}$ and $Q ; 6$ ) availability of explicit current output (i.e. high impedance output node) without requiring any additional active elements; 7) no requirement of components matching conditions to get all filtering responses; 8) no requirements of inverting-type input current signal(s) and double input current signal(s) to realize the filtering response(s) in the design, all of which are not available simultaneously in any of the previously reported current-controlled current-mode biquad filter of [15-27]. With above mentioned features, it is very suitable to realize the proposed circuit in monolithic chip to use in battery powered, portable

Table 1. The SPICE model parameters of MOSFET for level 3, $0.35 \mu \mathrm{m}$ CMOS process from TSMC.

\begin{tabular}{ll}
\hline & $\mathrm{LEVEL}=3 \mathrm{TOX}=7.9 \mathrm{E}-9 \mathrm{NSUB}=1 \mathrm{E} 17 \mathrm{GAMMA}=0.5827871 \mathrm{PHI}=0.7 \mathrm{VTO}=0.5445549 \mathrm{DELTA}=0 \mathrm{UO}=$ \\
& $436.256147 \mathrm{ETA}=0 \mathrm{THETA}=0.1749684 \mathrm{KP}=2.055786 \mathrm{E}-4 \mathrm{VMAX}=8.309444 \mathrm{E} 4 \mathrm{KAPPA}=0.2574081 \mathrm{RSH}=$ \\
& $0.0559398 \mathrm{NFS}=1 \mathrm{E} 12 \mathrm{TPG}=1 \mathrm{XJ}=3 \mathrm{E}-7 \mathrm{LD}=3.162278 \mathrm{E}-11 \mathrm{WD}=7.046724 \mathrm{E}-8 \mathrm{CGDO}=2.82 \mathrm{E}-10 \mathrm{CGSO}=$ \\
& $2.82 \mathrm{E}-10 \mathrm{CGBO}=1 \mathrm{E}-10 \mathrm{CJ}=1 \mathrm{E}-3 \mathrm{~PB}=0.9758533 \mathrm{MJ}=0.3448504 \mathrm{CJSW}=3.777852 \mathrm{E}-10 \mathrm{MJSW}=0.3508721$ \\
& $\mathrm{LEVEL}=3 \mathrm{TOX}=7.9 \mathrm{E}-9 \mathrm{NSUB}=1 \mathrm{E} 17 \mathrm{GAMMA}=0.4083894 \mathrm{PHI}=0.7 \mathrm{VTO}=-0.7140674 \mathrm{DELTA}=0 \mathrm{UO}=$ \\
& $212.2319801 \mathrm{ETA}=9.999762 \mathrm{E}-4 \mathrm{THETA}=0.2020774 \mathrm{KP}=6.733755 \mathrm{E}-5 \mathrm{VMAX}=1.181551 \mathrm{E} 5 \mathrm{KAPPA}=1.5$ \\
& $\mathrm{RSH}=30.0712458 \mathrm{NFS}=1 \mathrm{E} 12 \mathrm{TPG}=-1 \mathrm{XJ}=2 \mathrm{E}-7 \mathrm{LD}=5.000001 \mathrm{E}-13 \mathrm{WD}=1.249872 \mathrm{E}-7 \mathrm{CGDO}=3.09 \mathrm{E}-10$ \\
& $\mathrm{CGSO}=3.09 \mathrm{E}-10 \mathrm{CGBO}=1 \mathrm{E}-10 \mathrm{CJ}=1.419508 \mathrm{E}-3 \mathrm{~PB}=0.8152753 \mathrm{MJ}=0.5 \mathrm{CJSW}=4.813504 \mathrm{E}-10 \mathrm{MJSW}=$ \\
& 0.5
\end{tabular}




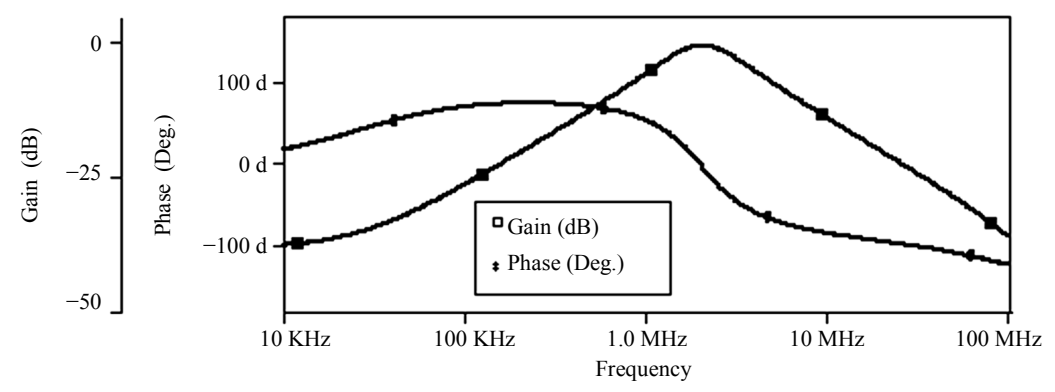

(a)

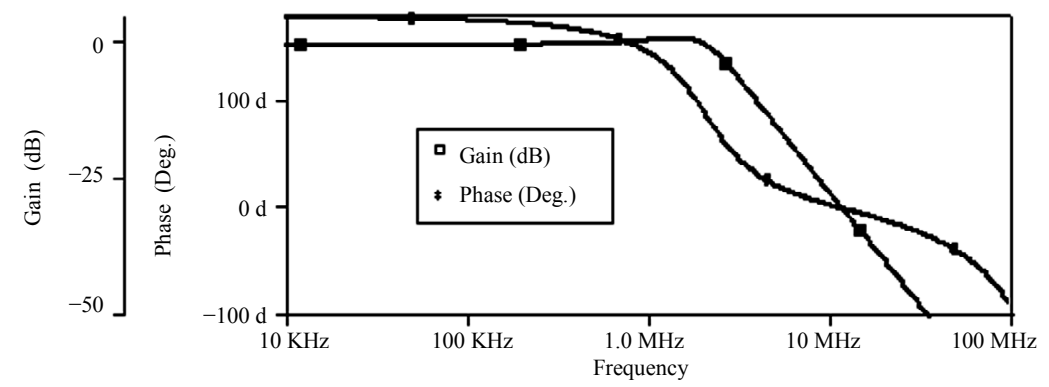

(b)

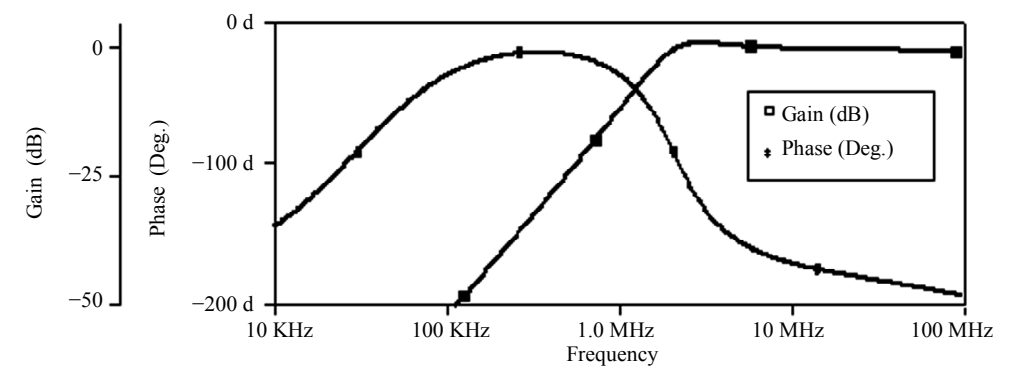

(c)

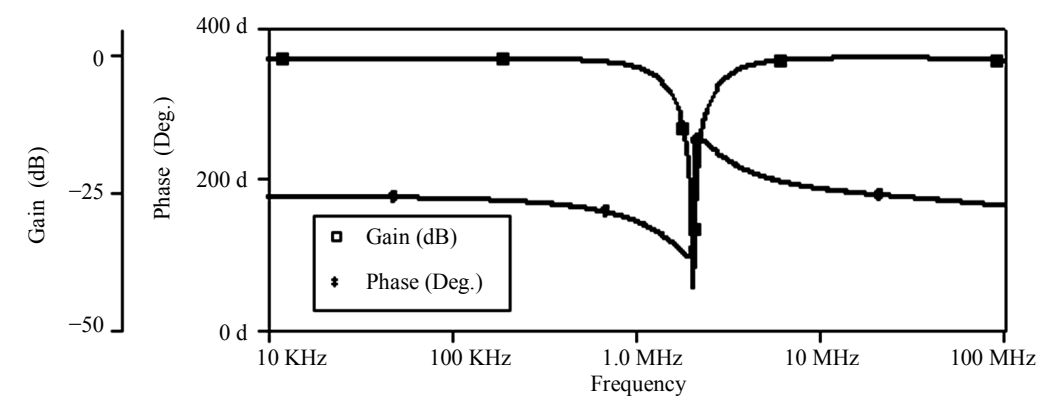

(d)

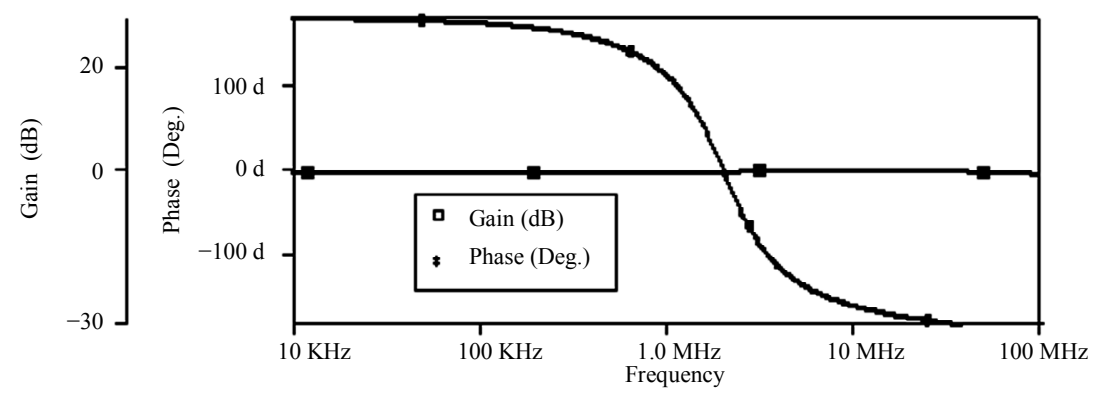

(e)

Figure 4. Current gain and phase responses of the (a) BP, (b) LP (c) HP (d) BR (e) AP for the proposed biquad filter in Figure 3. 


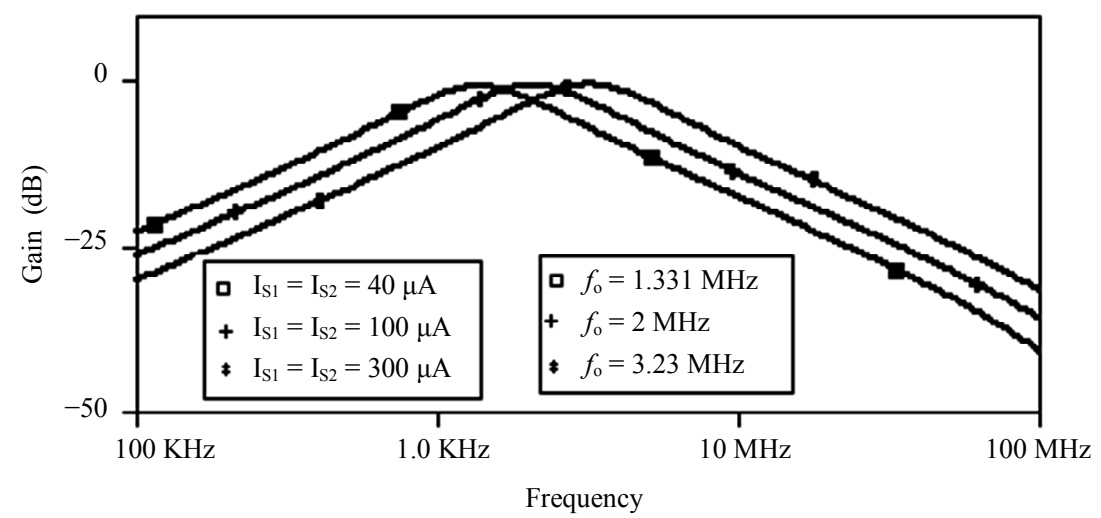

Figure 5. BP responses for different value of $I_{S 1}=I_{S 2}$ to show the electronic tunability of pole frequency.

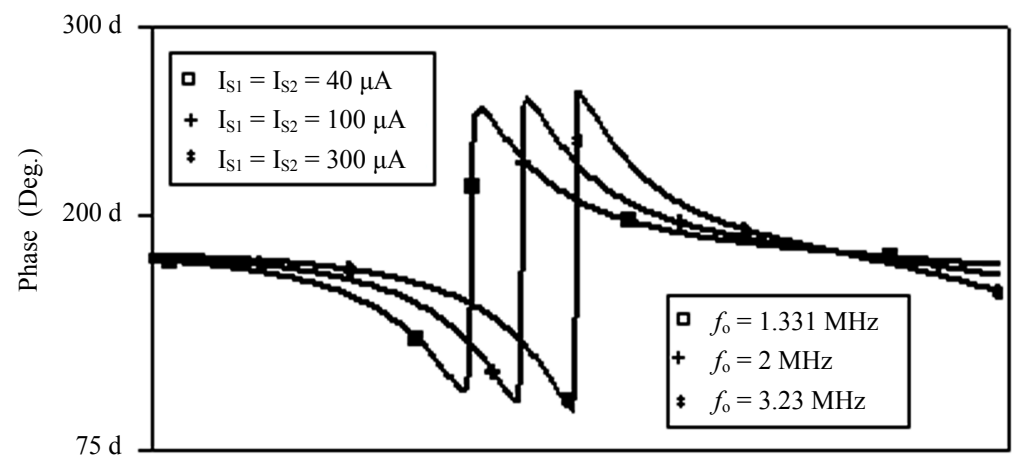

(a)

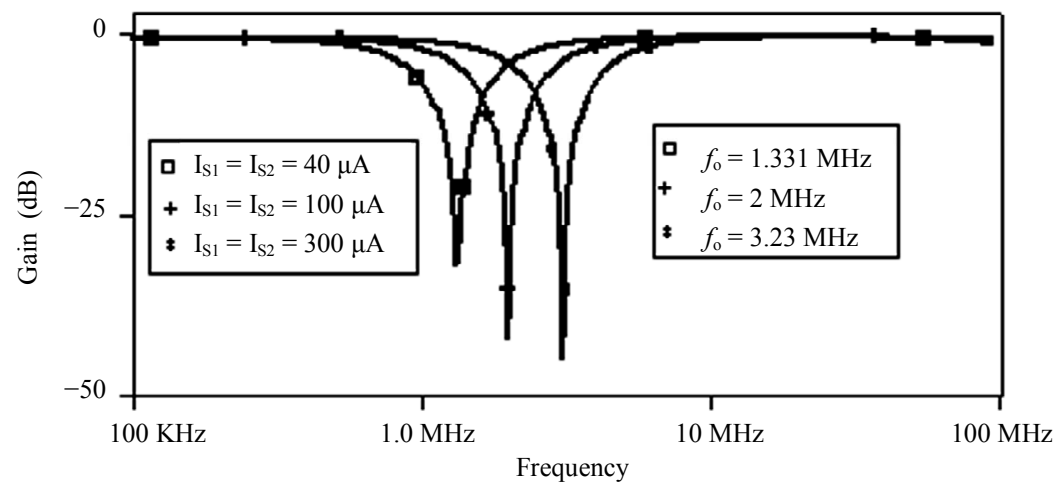

(b)

Figure 6. BR responses (a) Gain (b) Phase, for different value of $I_{S 1}=I_{S 2}$ to show the electronic tunability of pole frequency.

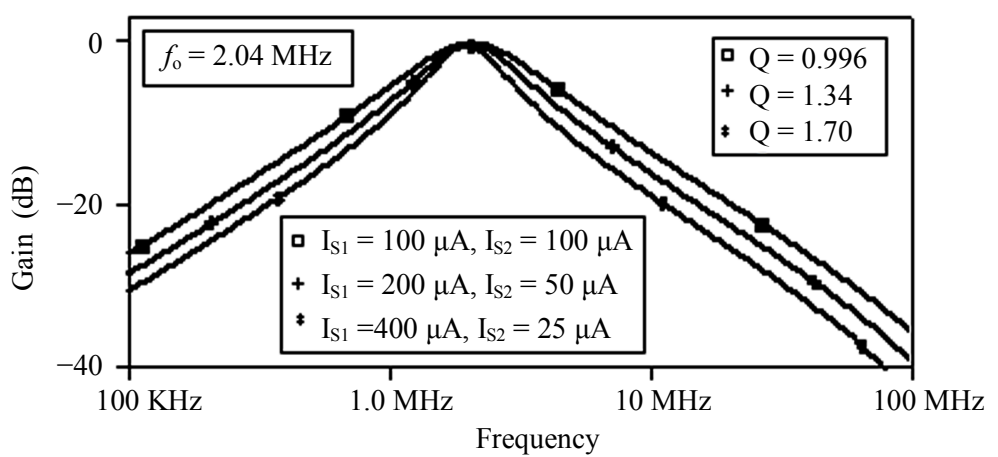

Figure 7. BP responses for different value of $I_{S 1}$ and $I_{S 2}$ to show the electronic tunability of quality factor. 


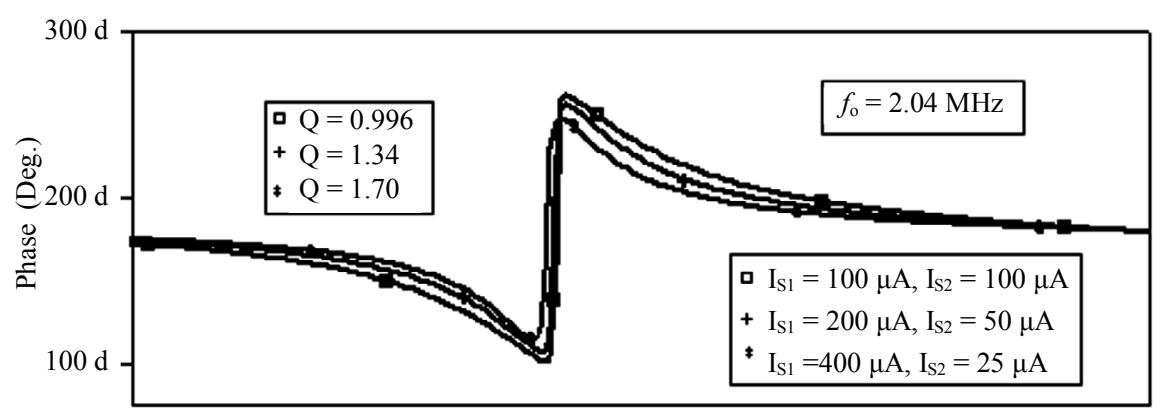

(a)

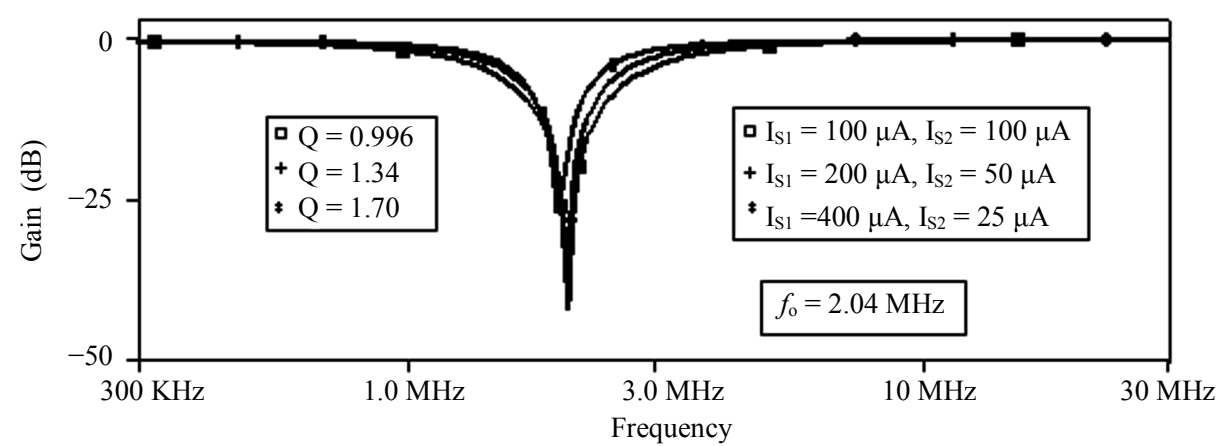

(b)

Figure 8. BR responses (a) gain (b) phase, for different value of $I_{S 1}$ and $I_{S 2}$ to show the electronic tunability of quality factor.

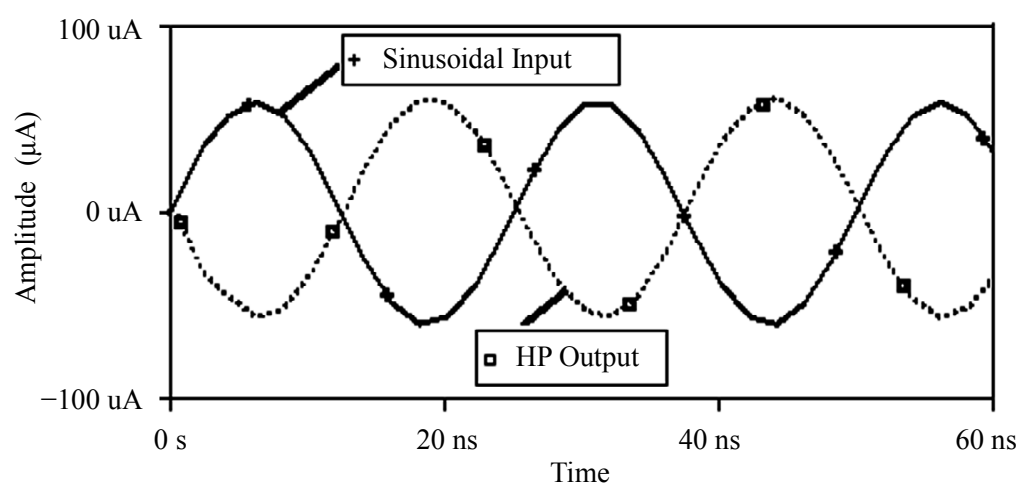

Figure 9. The time domain input waveform and corresponding response at HP current output.

electronic equipments such as wireless communication system devices.

\section{REFERENCES}

[1] B. Wilson, "Recent Developments in Current Conveyors and Current Mode Circuits," IEE Proceeding-G, Vol. 137, No. 2, 1990, pp. 63-77.

[2] M. A. Ibrahim, S. Minaei and H. A. Kuntman, "A 22.5 $\mathrm{MHz}$ Current-Mode KHN-Biquad Using Differential Voltage Current Conveyor and Grounded Passive Elements," Int'l J. Electronics and Communication (AEÜ), Vol. 59, No. 5, 2005, pp. 311-318. http://dx.doi.org/10.1016/j.aeue.2004.11.027

[3] A. M. Soliman, "Current Mode Universal Filter," Electronics Letters, Vol. 31, No. 17, 1995, pp. 1420-1421. http://dx.doi.org/10.1049/el:19951018

[4] R. Senani, V. K. Singh, A. K. Singh and D. R. Bhaskar, "Novel Electronically Controllable Current Mode Universal Biquad Filter," IEICE Electronics Express, Vol. 1, No. 14, 2004, pp. 410-415. http://dx.doi.org/10.1587/elex.1.410

[5] S. Maheshwari, S. V. Singh and D. S. Chauhan, "Electronically Tunable Low Voltage Mixed-Mode Universal Biquad Filter," IET Circuits, Devices and Systems, Vol. 5, No. 3, 2011, pp. 149-158. http://dx.doi.org/10.1049/iet-cds.2010.0061

[6] M. T. Abuelma'atti and A. M. Shabra, "A Novel Current Conveyor-Based Universal Current-Mode Filter," Microelectronics Journal, Vol. 27, No. 6, 1996, pp. 471-475. http://dx.doi.org/10.1016/0026-2692(95)00108-5

[7] S. Minaei and S. Türköz, "New Current-Mode Current- 
Controlled Universal Filter with Single Input and Three Outputs," Int'l J. Electronics, Vol. 88, No. 3, 2001, pp. 333-337. http://dx.doi.org/10.1080/00207210010013201

[8] A. U. Keskin, D. Biolek, E. Hancioglu and V. Biolkova, "Current-Mode KHN Filter Employing Current Differencing Transconductance Amplifiers," Int'l J. Electronics and Communications, Vol. 60, No. 6, 2006, pp. 443-446. http://dx.doi.org/10.1016/j.aeue.2005.09.003

[9] S. V. Singh, S. Maheshwari and D. S. Chauhan, "Universal Current-Controlled Current-Mode Biquad Filter Employing MO-CCCCTAs and Grounded Capacitors," Journal of Circuits, Systems, and Computers, Vol. 1, 2010, pp. 35-40. http://dx.doi.org/10.4236/cs.2010.12006

[10] T. Tsukutani, Y. Sumi, S. Iwanari and Y. Fukui, "Novel Current-Mode Biquad Using MO-CCCIIs and Grounded Capacitors," Proceeding of 2005 Symposium on Intelligent Signal Processing and Communication (ISPACS), Hong Kong, 13-16 December 2005, pp. 433-436. http://dx.doi.org/10.1109/ISPACS.2005.1595439

[11] B. Singh, A. K. Singh and R. Senani, "New Universal Current-Mode Biquad Using Only Three ZC-CFTA," Radioengineering, Vol. 21, No. 1, 2012, pp. 273-280.

[12] D. Biolek and V. Biolkova, "CDTA-C Current-Mode Universal 2nd Order Filter," Proceeding of the 5th WSEAS Int'l Conference on Applied Informatics and Communications, Malta, 15-17 September 2005, pp. 411-414.

[13] N. Herencsar, J. Koton and K. Vrva, "Single CCTABased Universal Biquad Filters Employing Minimum Components," International Journal of Computer and Electrical Engineering, Vol. 1, No. 3, 2009, pp. 307-310.

[14] B. Metin, "Electronic Tunability in Analog Filters," Ph.D. Thesis, Bogazici University, Istanbul, 2007.

[15] W. Tangsriart and W. Surakampontorm, "Low Component Current-Mode Universal Filter Using Current Controlled Conveyors and Grounded Capacitors," Journal of Active and Passive Electronic Devices, Vol. 8, 2009, pp. 259-264.

[16] M. Kumngem, J. Chanwutitumt and K. Dejhan, "Current-Tunable Current-Mode Universal Filter Using Minimum Elements," Proceeding of the 6th IEEE Int'l Conference on Electrical Engineering/Electronics and Information Technology (ECRI-CON), Pattaya, 6-9 May 2009, pp. 582-585.

http://dx.doi.org/10.1109/ECTICON.2009.5137074

[17] E. Yuce, A. Kircay and S. Tokat, "Universal Resistorless Current-Mode Filters Employing CCCIIs," Int'l Journal of Circuit Theory and Applications, Vol. 36, No. 5-6, 2008, pp. 739-755. http://dx.doi.org/10.1002/cta.455
[18] W. Tangsriart and W. Surakampontorm, "Electronically Tunable Current-Mode Universal Filter Employing Only Plus-Type Current-Controlled Conveyors and Grounded Capacitors," Circuits Systems and Signal Processing, Vol. 25, No. 6, 2006, pp. 701-713. http://dx.doi.org/10.1007/s00034-005-0908-y

[19] N. Jangsamsi, T. Pukkalanun and W. Tangsrirat, "CCCIIBased High-Output Impedance Current-Mode Universal Filter Employing Only Grounded Capacitors," SICEICASE International Joint IEEE Conference, Busan, 1821 October 2006, pp. 5695-5698. http://dx.doi.org/10.1109/SICE.2006.314635

[20] M. T. Abuelma'atti and M. L. Al-qahtani, "Universal Current-Contolled Current-Mode Filter with Three Inputs and One Output Using Current Controlled Conveyor," Active Passive Electronic Components, Vol. 21, No. 1, 1998, pp. 33-41. http://dx.doi.org/10.1155/1998/83413

[21] C. M. Chang, T. H. Huang, S. H. Tu, C. L. Hou and J. W. Horng, "Universal Active Current Filter Using Single Second-Generation Current Controlled Conveyor," Circuits, Systems and Signal Processing, Vol. 1, No. 2, 2007, pp. 194-198.

[22] W. Tangsrirat, T. Dumawipata and W. Surakampontorn, "Multiple-Input Single-Output Current-Mode Multifunction Filter Using Current Differencing Transconductance Amplifiers," Int'l Journal of Electronic and Communication (AË̈), Vol. 61, No. 4, 2007, pp. 209-214. http://dx.doi.org/10.1016/j.aeue.2006.04.004

[23] S. Lawnwisut and M. Siripruchyanun, "A Current-Mode Multifunction Biquadratic Filter Using CFTAs," Journal of King Mongkut's University of Technology, North Bangkok, Vol. 22, No. 3, 2012, pp. 479-484.

[24] J. Satansup, T. Pukkalanum and W. Tangsrirat, "Electronically Tunable Current-Mode Universal Filter Using VDTAs and Grounded Capacitors," Proceeding of the International Multiconference of Engineers and Computer Scientists, Hongkong, 13-15 March 2013, pp. 6-9.

[25] T. Thosdeekoraphat, S. Summart, C. Saetiaw, S. Santalunai and C. Thongsopa, "Resistor-Less Current-Mode Universal Biquad Filter Using CCTAs and Grounded Capacitors," World Academy of Science, Engineering and Technology, Vol. 69, 2012, pp. 559-563.

[26] W. Jaikla, S. Siripongdee and P. Suwanjan, "MISO Current-Mode Biquad Filter with Independent Control of Pole Frequency and Quality Factor," Radioengineering Journal, Vol. 21, No. 3, 2012, pp. 886-891.

[27] S. V. Singh and S. Maheshwari, "Current-Processing Current Controlled Universal Biquad Filter," Radioengineering Journal, Vol. 21, No. 1, 2012, pp. 317-323. 